\title{
Steffen Bruendel, Zeitenwende 1914. Künstler, Dichter und Denker im Ersten Weltkrieg
}

München : Herbig, 2014, 304 p., $20 €$.

\section{Bérénice Zunino}

\section{CpenEdition}

\section{Journals}

Édition électronique

URL : http://journals.openedition.org/ifha/8416

DOI : 10.4000/ifha.8416

ISSN : 2198-8943

Éditeur

IFRA - Institut franco-allemand (sciences historiques et sociales)

Référence électronique

Bérénice Zunino, «Steffen Bruendel, Zeitenwende 1914. Künstler, Dichter und Denker im Ersten Weltkrieg », Revue de l'IFHA [En ligne], Date de recension, mis en ligne le 01 février 2016, consulté le 22 septembre 2020. URL : http://journals.openedition.org/ifha/8416; DOI : https://doi.org/10.4000/ifha. 8416

Ce document a été généré automatiquement le 22 septembre 2020.

(CIFHA 


\section{Steffen Bruendel, Zeitenwende 1914. Künstler, Dichter und Denker im Ersten Weltkrieg}

München : Herbig, 2014, 304 p., $20 €$.

\section{Bérénice Zunino}

Riche et concis, cet ouvrage de synthèse qui s'adresse à un large public dresse un panorama de l'histoire des intellectuels en Allemagne et en Autriche-Hongrie à l'époque de la Première Guerre mondiale. Témoignages d'artistes à l'appui, Steffen Bruendel y retrace la manière dont ceux-ci perçurent la guerre tout en accordant une vaste place au contexte politique et militaire (évolution politique des empires allemands et autrichiens, difficultés économiques croissantes à l'arrière, etc.). Pour écrire l'histoire culturelle des intellectuels durant le conflit, comprise ici comme une histoire des représentations, il s'inscrit dans la lignée de Modris Eksteins (Le Sacre du printemps. La Grande Guerre et la naissance de la modernité. Paris: Plon, 1991 [1989]) et de Florian Illies (1913: Chronique d'un monde disparu. Paris : Piranha, 2014 [2012]) : il y décrit la mobilisation militaire et intellectuelle, mais aussi l'engagement pacifiste, en proie à la censure et à l'autocensure, des peintres, écrivains, philosophes, universitaires et scientifiques durant cette période charnière qui inaugura la Modernité. De Richard Dehmel à Erich Mühsam en passant par Hugo von Hofmannsthal, Alois Riehl et Fritz Haber, l'auteur présente les espoirs, les questionnements et les désillusions des intellectuels de l'époque. On peut seulement regretter l'absence d'un index des noms qui aurait facilité l'orientation du lecteur.

L'ouvrage se divise en cinq chapitres thématiques qui retracent aussi la chronologie de l'avant-1914 et du conflit: "Abglanz» ("éclats »), "Aufbruch » (« sursaut »), «Umbruch» («bouleversements ), «Aufbau " (« réorganisation») et «Abgang» (« déclin »). La prise en compte de l'avant-guerre permet de comprendre dans quel contexte littéraire, artistique, scientifique et politique le conflit éclata et de mieux cerner les craintes et les espoirs de renouveau qu'il suscitait. En remémorant au lecteur des extraits de poèmes célèbres, l'auteur présente les visions apocalyptiques des 
artistes d'avant-garde tels que Georg Heym, Jakob von Hoddis et Ludwig Meidner dans les capitales culturelles que furent Munich et Vienne. Il illustre également la «polarisation idéologique » (p. 30) de la société par la querelle des frères Heinrich et Thomas Mann.

Cette plongée dans l'avant-1914 permet à S. Bruendel dans les deux chapitres suivants de relativiser la césure que représenta le conflit: convaincus de la nécessité d'une guerre défensive, nombre d'intellectuels s'engagèrent volontairement en 1914 et soutinrent la propagande dont les atrocités, allemandes ou alliées, représentaient dans les deux camps un thème central. Source d'inspiration, les hostilités ne générèrent pas seulement un art au service de la propagande mais aussi un art contre la guerre, comme en témoignent les œuvres de George Grosz, Walter Hasenclever, Willy Jaeckel, August Stramm ou encore Ernst Toller ; parallèlement à la poursuite de la propagande, l'année 1916 marqua un tournant pour de nombreux artistes dont l'exemple le plus connu est sans doute celui de Bertolt Brecht. S. Bruendel voit dans ce tournant un affaiblissement des représentations héroïques (p. 131). Pourtant, ce modèle suranné et les formes traditionnelles qui l'accompagnent, dont la disparition est souvent associée à la Première Guerre mondiale, semble persister bien au-delà de 1918 (voir notamment: Claire Aslangul, Représentations de la guerre chez les peintres, graveurs et dessinateurs allemands au XXe siècle, dans le contexte européen: traditions, évolutions et ruptures dans les codes iconographiques. Thèse de doctorat préparée sous la direction de Jacques Le Rider et de Gerd Schwerhoff, École Pratique des Hautes Etudes, Paris et Technische Universität, Dresde, 2003. Jay Winter, Entre deuil et mémoire. La Grande Guerre dans l'histoire culturelle de l'Europe. Paris : Colin, 2008 [1995]). La place importante que l'auteur accorde à l'art contre la guerre constitue néanmoins un atout précieux de cet ouvrage.

Si les peintres et écrivains y font l'objet d'une attention particulière, le quatrième chapitre («Aufbau») est principalement consacré aux «idées de 1914 », aux universitaires et penseurs politiques et économistes. Y sont résumés les projets de réforme politique de l'État (Johann Plenge, Rudolf Kjellén, Hugo Preuß) qui accentuèrent les débats autour de la démocratisation et de la parlementarisation de l'empire allemand, ainsi que les autres tentatives, à l'instar de celle de l'économiste Werner Sombart, de se démarquer des puissances occidentales, particulièrement de l'Angleterre.

En retraçant l'instabilité politique et les difficultés économiques croissantes durant les dernières années de guerre en Allemagne et en Autriche-Hongrie, S. Bruendel montre enfin la désillusion de nombreux intellectuels, les traumatismes de ceux exposés à la violence du champ de bataille, leurs dépressions et leurs derniers espoirs déçus après les offensives du printemps 1918. Ce traitement chrono-thématique donne lieu à des parallèles fructueux entre l'évolution politique et l'engagement des intellectuels: l'auteur mentionne la formation de "soviets des arts " ("Arbeitsräte für Kunst ", p. 227) qui visaient à épauler en novembre 1918 les conseils de soldats et d'ouvriers dans leur tentative révolutionnaire. Parmi les intellectuels des avant-gardes qui s'engagèrent enfin pour un renouveau démocratique et pacifiste, nombreux furent ceux, comme le souligne S. Bruendel dans son épilogue, dont les œuvres devaient être qualifiées à peine une décennie plus tard de "dégénérées" et bannies par les nationaux-socialistes.

Vous trouverez la table des matières ici : http://d-nb.info/104522958x/04. 
INDEX

Index chronologique : Époque contemporaine

Thèmes : Histoire de l'art, Histoire de la culture, Histoire des sciences

\section{AUTEUR}

BÉRÉNICE ZUNINO

Institut français d'histoire en Allemagne, Francfort-sur-le-Main 